J. Gynäkol. Endokrinol. AT 2020 · 30:28

https://doi.org/10.1007/s41974-020-00130-2

(c) Springer-Verlag GmbH Austria, ein Teil von Springer Nature 2020
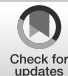

Franz Fischl

Wien, Österreich

\title{
Stellungnahme des Herausgebers
}

krebs, Hirntumore, Morbus Parkinson, Schlaganfall, Epilepsie) wurde und wird in kleinen Studien erprobt. Entsprechende Geräte wurden und werden in Ländern wie Frankreich, Deutschland und Amerika entwickelt und erzeugt. Entsprechend sehr zahlreich ist auch die weltweite internationale Literatur, auf die im folgenden Artikel nicht eingegangen wird.

Da der Autor, wie er am Beginn der Arbeit ankündigt, eine Zusammenarbeit mit China anstrebt, wäre es umso wünschenswerter, sich im Vergleich mit den internationalen europäischen und anglikanischen Daten auseinander zu setzen und die Techniken und Geräte auf Grund der zahlreichen vorhandenen Arbeiten zu vergleichen. Nur so ließe sich feststellen, ob hier vom chinesischen Team ein völlig neuer Weg eingeschlagen wird oder es nur ein weiteres Angebot auf diesem Gebiet ist.

\section{Franz Fischl}

Herausgeber

\section{Korrespondenzadresse}

Prof. Dr. Franz Fisch

Wien, Österreich

franz.fischl@meduniwien.ac.at

Interessenkonflikt. F. Fischl gibt an, dass kein Interessenkonflikt besteht.

Hinweis des Verlags. Der Verlag bleibt in Hinblick auf geografische Zuordnungen und Gebietsbezeichnungen in veröffentlichten Karten und Institutsadressen neutral.

Hier steht eine Anzeige.

橧) Springer 